\title{
Youth Access Clinics In Gippsland: Barriers and Enablers to Service Accessibility in Rural Settings
}

RUNNING TITLE: Barriers and enablers in access to rural youth services

\author{
Erin Dolan ${ }^{1,2}$, Kelly Allott ${ }^{1,2}$, Amanda Proposch ${ }^{3}$, Matthew Hamilton ${ }^{1,2}$, and Eoin \\ Killackey $^{1,2 *}$
}

${ }^{1}$ Orygen, The National Centre of Excellence in Youth Mental Health, Parkville, Victoria, Australia

${ }^{2}$ Centre for Youth Mental Health, The University of Melbourne, Parkville, Victoria, Australia ${ }^{3}$ Primary Health Network Gippsland, Traralgon, Victoria, Australia

*Corresponding author: Professor Eoin Killackey, 35 Poplar Road, Parkville, VIC, 3052;

eoin.killackey@orygen.org.au; Ph: 0399669420

This is the author manuscript accepted for publication and has undergone full peer review but has not been through the copyediting, typesetting, pagination and proofreading process, which may lead to differences between this version and the Version of Record. Please cite this article as doi: 10.1111/eip.12949

This article is protected by copyright. All rights reserved. 


\begin{abstract}
Background: Approximately 15 years ago four Youth Access Clinics were established in the Gippsland region to improve mental and general healthcare for young people living in the region. The aim of the study was to examine the barriers and enablers for young people accessing the Youth Access Clinics in Gippsland. Methods: Using qualitative methodology, 9 female YAC staff members and 7 youth YAC consumers were interviewed. Thematic analysis was utilised to identify important and consistent themes in the data derived through the consultation process. Results: Barriers under four themes were identified: environmental (e.g., limited transport); service (i.e., limited opening hours); client (e.g., parent permission) and staff (i.e., retention of staff). Enablers were identified as environmental (i.e., high social proximity); service (e.g., funding); client (i.e., awareness of service) and staff (e.g., champion staff). Discussion: The success of new rural service models will likely depend on learning from what has already worked in some of the many small communities in this region. Beyond learning, further success and uptake of new service offerings will be enhanced through understanding community needs, obtaining community support and enhancing high social proximity.
\end{abstract}

Key words: Youth mental health; Social proximity; Qualitative methods; Service models; Risk factors

This article is protected by copyright. All rights reserved. 
Residing in a rural community poses many challenges for young people. These include a lack of access to community care and professional assistance, insufficient financial resources, fear of stigma, limited confidentiality and geographical isolation (Boyd et al., 2006; Curtis, Waters, \& Brindis, 2011; Hardy, Kelly, \& Voaklander, 2011). These challenges are likely to have a significant influence on service accessibility and a young person’s perception of their mental health and its severity. With the increased awareness and prevalence of youth mental health problems in Australia, it is essential for commissioners, researchers and professionals alike to understand the influence of barriers and enablers on service accessibility in order to develop new youth-focused programs that meet the complex needs of rural adolescents (Boyd et al., 2006; Hardy et al., 2011).

Unlike top-down process in which commissioners, policy makers, or other organisations decide on a location and establish a site for a service, for rural services to be successful, there is a need for input and support from the community and for the service to be a part of the community (Sullivan et al., 2005; Xu \& Chow, 2006). In essence, this entails a bottom-up approach - growing instead of arriving, actively seeking to find ways to overcome stigma, promote availability and openness of the service and at the same time, ensure confidentiality (Sullivan et al., 2005; Turner et al., 2017).

Despite the introduction of innovative services such as telehealth to enhance accessibility and improve the quality of services in rural areas, internet black spots, limited mobile reception, concerns around confidentiality and impersonal treatment, often reduce the success of these services being integrated into rural communities (Clarke, Kuosmanen, \& Barry, 2015; Gibson et al., 2011; Myers \& Cornor, 2016). Thus, supporting a bottom-up 
approach in rural communities can help integrate the use of telehealth technologies and guide development of services which are community and geographically sensitive to the local region (Gibson et al., 2011).

Understanding young people’s perspectives on service barriers and enablers is an essential component when designing and delivering successful and accessible services in rural areas. Research conducted by Boyd et al. (2006) showed that young people identified a number of barriers that prevented them from accessing support. These included: lack of transport, finances (unemployment), confidentiality concerns, lack of knowledge surrounding services available, limited female general practitioners, minimal bulk-billing and free services, inexperienced health care professionals, reduced choice of treatment providers and long waiting lists. Other studies showed young people reported concerns surrounding the need for parental consent, embarrassment of parental involvement and feelings of being a burden due to parents working and having limited time (Chan et al., 2016; Edwards, Theriault, Shores, \& Melton, 2014; Ervin, Phillips, \& Tomnay, 2014).

Confidentiality and high social proximity within a rural community are essential when creating successful youth services and reducing barriers (Hodges Craig, O'Brien Matthew, \& McGorry Patrick, 2007; Sawyer et al., 2001). Social proximity refers to an individual’s interpersonal relationship with others, groups and wider community (Ervin et al., 2014). High social proximity can aid in the early detection of behaviour change and identification of mental health symptoms (Aisbett, Boyd, Francis, Newnham, \& Newnham, 2007; Boyd et al., 2011). Whereas, low social proximity can prevent a young person from accessing care due to concerns for confidentiality and feeling ostracised by the community (Aisbett et al., 2007; 
Ervin et al., 2014; Sawyer et al., 2001). Most studies to date however, report on the negative impact of social proximity and the barriers it causes for a young person when accessing services (Curtis et al., 2011; Ervin et al., 2014; Sawyer et al., 2001).

When developing youth services in rural areas, outreach services based on the needs of young people are recommended. The importance of working within the community to provide local solutions is also identified, although insufficient funding can often impact on the program’s sustainability (Edwards et al., 2014; Hodges, O'Brien, \& McGorry, 2007). Financial constraints often lead to non-youth specific spaces, where the youth program shares facilities with older populations. Research shows that shared space can discourage young people from accessing support (Ervin et al., 2014).

An example of a bottom-up service delivery approach is that developed by four communities in Gippsland, Victoria (Foster, Korumburra, Leongatha and Wonthaggi) (Figure 1). Approximately 15 years ago, each community developed a Youth Access Clinic (YAC) in order to respond to perceived youth needs, reduce barriers, enhance access and improve care for all young people in the region. Gippsland Primary Health Network and the South Coast Primary Care Partnerships provided support and funding to the YACs and facilitated the creation of the YAC consortium. The aim of the consortium was to share knowledge and resources, enhance risk management, attract funding on a larger scale, provide a common logo, website, and frame of reference, as well as collect data from each of the youth clinics. The YAC consortium is made up of partnerships between the four YACs, the Department of Education, South Coast Primary Care Partnership and the Gippsland Primary Health Network (https://www.southcoastyouthclinics.com.au/). The success of the YACs helped justify the 
funding for Wonthaggi headspace, demonstrating the need for youth services in Gippsland. As headspace continues to expand across Australia, it is likely that a proportion of future growth will incorporate regional and rural settings. The aim of this research was to examine the barriers and enablers for young people accessing support and identify local and non-local factors that either contribute to or hinder the success of clinics such as the YACs. It is hoped that the findings of this qualitative study will inform the development and success of future rural youth-focussed clinics.

This article is protected by copyright. All rights reserved. 


\section{Method}

\section{Sample}

Participants were recruited from the four YACs in Gippsland. The sample consisted of 9 female YAC staff members, with a mean age of 46.11 years (range 37-54 years). Staff included practice nurses, program managers and general practitioners. Each staff member was identified by the consortium as having in-depth knowledge of the YACs. The 7 youth participants (6 female and 1 male; mean age 17.42 range 15-20 years) were consumers of the YACs and volunteered to participate in the study in response to study advertisements. No participants identified as Aboriginal or Torres Strait Islander.

\section{$\underline{\text { Design }}$}

Participants engaged in individual semi-structured interviews (Crouch, 2006). Thematic analysis was utilised to identify important and consistent themes across the dataset, which was derived through the consultation process (Braun \& Clarke, 2012). The data analysis was conducted in six phases as outlined by Braun and Clarke (2012). These phases include, familiarisation with the data, generating initial codes, searching for themes among codes, reviewing themes, defining and naming themes, and producing the final report.

\section{Materials}

The researchers and the YAC consortium (4 nurses, 2 practice managers, primary care partnership case worker, Department of education psychologist) developed two semistructured interview schedules, one for staff and one for young people, which aimed to identify barriers and enablers to accessing care in rural settings. Examples of questions for 
young people included: Is YAC important in your area? If so, why? If not why?; What makes it easier for you to access YAC? What makes it harder for you to access YAC?. Staff interview questions included: How did they identify the need for the YAC?; What makes it easier for your YAC to run its service?; Do you struggle with recruiting any particular clinician from any field? Why? What are the barriers?

\section{Procedure}

Ethics approval was obtained from the University of Melbourne Psychology Health and Applied Sciences Human Ethics Sub-Committee (Approval \#1750770).

Participants provided written informed consent and were interviewed by the researcher either face-to-face (13 interviews) or via the telephone (3 interviews). Interviews took between 30-90 minutes. Interviews were audio-recorded and transcribed verbatim.

\section{$\underline{\text { Analysis }}$}

Interviews were analysed according to Braun and Clarke (2012) guidelines. QSR NVivo 11 aided coding and analysis processes. Thematic maps were used to highlight relationships between themes (Braun \& Clarke, 2012). All interviews were rechecked to validate the final themes (Guest, Bunce, \& Johnson, 2006). Supervision and discussions with the YAC consortium and co-authors ensured transparency and rigour of data analysis. A reflexivity journal was maintained throughout the research process, documenting observations, reflections, decisions and processes and were used to question assumptions made in interpreting and coding the data (Braun \& Clarke, 2012). 


\section{Results}

\section{Barriers to Accessing Care}

\section{Environmental Barriers}

There were a number of environmental barriers identified by young people and YAC staff (Figure 2). The main theme highlighted by staff was the lack of services for young people in the South Gippsland area. Staff stressed the need for "geographically feasible” S2 services for young people as many are reliant on public transport to access services. Young people agreed with the above barriers, in particular transport barriers by stating “... you have to be really mindful of the buses if you're taking the bus" YP4. Other barriers highlighted in Figure 2 are lack of services in areas such as Phillip Island, internet black spots and lack of mobile reception.

\section{$\underline{\text { Service Barriers }}$}

Figure 3 provides a summary of perspectives on service barriers. Young people reported limited opening hours as being a significant barrier to accessing services. Comments such as “...nothing's open after school, everything closes at 5 ” YP2 and “...there was quite a big wait when you came in and sometimes they couldn't get around to you" YP4 highlighted this. Staff agreed with the limited opening hours and need to be flexible, however statements such as "Opening from 12.30 to 4.30. We were really strict on that because I had to go and pick our kids up" S2 highlighted the conflicting responsibilities of professionals.

This article is protected by copyright. All rights reserved. 
Other service barriers highlighted were the lack of general practitioners, counsellors and female doctors.

\section{Client Barriers}

Young people were concerned about parents needing to approve access to YACs. For example "kids weren't able to go there because they had to get signed permission from their parents” YP4. Staff also identified parents as a significant barrier by highlighting the need for “risk management around a parent not being happy about their child going” S3. Young people also discussed concerns about low social proximity with parents being in the YAC waiting room, for example, "I'm not going to go and grab it while my friend's mum is just sitting there” YP1. Stigma was also highlighted with “...friends have found it awkward” YP1. Figure 4 provides a summary of client barriers.

\section{$\underline{\text { Staff Barriers }}$}

The recruitment and retention of champions was a significant barrier across all YACs. Comments such as "concept of a youth clinic but nobody was really prepared to devote themselves to it" S4, highlighted barriers with recruitment and the direct impact this barrier has on the clinic's success. Non-youth friendly staff were also identified as barriers: “he'd turn up and then kids wouldn't turn up” S5. A number of staff emphasized the high potential for burnout. Comments included the feeling of being “not just GP but counsellor, social worker, advocate which is all part of our brief" S1. Other factors that led to burnout in staff were urban doctors “... didn't have that sense of community” S6 and limited mental health professionals, i.e., "few psychologists who deal with youth health” S1.

This article is protected by copyright. All rights reserved. 


\section{Enablers}

\section{Environmental Enablers Built on Community}

Environmental enablers such as community support, high social proximity, donations and financial support all aided in the survival of the programs. Staff stated "entire community is quite supportive” S4. This comment highlighted the essential partnership between communities and service providers. Young people identified environmental enablers such as centralised location and not having to travel: “...the main thing that appeals is that it's right near us” YP3.

\section{$\underline{\text { Service Enablers }}$}

Service enablers identified by young people included, "free access for services” YP 2 and “... bulk billed” YP4. They further addressed concerns around stigma by highlighting “...it's confidential and everyone’s there for a similar reason” YP1. Staff identified funding as the main service enabler, through statements such as "we run on the sniff of an oily rag," S5 and “... I can legitimately say I am being paid for this amount of time” S2. Staff further stated the creation of the consortium and forming of partnerships were essential service enablers.

\section{Client Enablers}

Word of mouth enhanced accessibility and knowledge of YACs, for example, "friends had mentioned it” YP3. Other enablers were the youth-friendly professionals and partnerships between YAC, schools and the wider community. For example, "they would ask 
me just anything, like just having a general conversation of what's been going on, or weekend or anything and it's just like “OK” and that's normal...” YP 3 and “...definitely support from the GP service and the school in sending young people to the service and also providing that medical support” S4. These enablers built trust in young people, e.g., “... it was there when I probably needed it” YP 1.

\section{Staff Enablers}

Staff qualities and approach to young people were extremely important in the success of the YACs. Furthermore, partnerships and teamwork were essential in sharing knowledge and information. Success was created from "key stakeholder knowing the right people, local knowledge, ground up approach, just building those relationships” S1. From the young persons’ perspective, staff qualities such as being approachable, nonjudgmental and making time were essential: “my GP doubled up as everything” YP2.

\section{Financial Enablers}

Funding was important for the continuation of YAC services. Their overall "goal was to get continual funding” S6. Comments such as “Gippsland PHN funding was absolutely instrumental in just trying to lift the profile but also just to get everyone to work together" S7. Community donations also helped YACs provided unique services such as purchasing scripts, “...food” and “...emergency support” S2. These donations were essential as prior to the Gippsland PHN funding, financial support from medical clinics and Bass Coast Health "guaranteed a shortfall for the doctor's day. So if they didn't have a certain amount of kids in then they'd cover that cost".

This article is protected by copyright. All rights reserved. 


\section{Discussion}

The aim of the present study was to identify the barriers and enablers of young people accessing youth-focused clinics and identify local and non-local factors that either facilitated or hindered the success of the YACs. While delivery of youth mental health services in rural settings has been explored, this is a unique study which examines a bottom up approach to addressing youth mental health service delivery in rural settings and provides valuable information concerning youth and staff perspectives on perceived barriers and enablers. A number of barriers and enablers to service delivery and accessibility were identified and provide insight into the creation of successful youth clinics, informed service needs and provide area specific considerations for the introduction of headspace to Wonthaggi and future rural youth-specific clinics.

The finding that a number of barriers influence young people's ability to attend youth services in a rural setting is consistent with previous research. Boyd et al. (2006) highlighted barriers such as lack of transport, finances, confidentiality concerns, limited female doctors, minimal free services, inexperienced health practitioners, long waiting lists and limited choice of practitioner. These barriers were reflected in the current study with participants expressing concerns around transport, geographical isolation and the reliance on caregivers for transport. In particular, young people felt restricted by the bus timetable and would often miss out on appointments due to the potential of being stranded if they missed the bus.

Similar to Boyd et al. (2006), young people and staff expressed concerns surrounding the high cost of travel and complicated bus routes, which create barriers to accessing services. The current study showed that the transport barriers led to young people relying on their 
parents for transportation. This is concerning as previous research has found that the reliance on parents can lead to young people feeling embarrassed, concerned about confidentiality, and fears of being a burden, which may in turn reduce help-seeking (Chan et al., 2016; Edwards et al., 2014; Ervin et al., 2014).

The study also identified the environmental barrier of mobile and internet blackspots. These blackspots can prevent rural programs such as the YACs from following models of best practice which includes health promotion and prevention with face-to-face and webbased supports (Clarke et al., 2015). It also creates barriers for young people accessing telepsychiatry, which was recommended by Boyd et al. (2006) as a solution to accessibility problems with specialists.

The present study is consistent with previous research highlighting the need for more female doctors, psychologists and counsellors (Aisbett et al., 2007; Boyd et al., 2006; Boyd et al., 2011). With the high rates of mental illness amongst youth in rural settings, unqualified or generic staff place young people at risk of disengagement from services, misdiagnosis and ineffective treatments (Degotardi, 2008; Fox, Merwin, \& Blank, 1995; Hodges et al., 2007). The integration of mental health nurses, psychologists, social workers and psychiatrists can create trust, reduce waiting list and increase service accessibility for young people as well as reduce the community perception of unqualified staff in rural settings (Boyd et al., 2006; Boyd et al., 2011).

Stigma, low social proximity and concerns surrounding confidentiality and parent involvement can directly impact on a young person's safety to access services (Aisbett et al., 
2007; Ervin et al., 2014). Consistent with previous research, the study highlighted young people were afraid of gossip, feeling intimidated and restricted by friend's parents being in the YAC waiting room. This type of low social proximity can lead to a young person refusing the service and feeling ostracised by the community (Ervin et al., 2014; Sawyer et al., 2001).

To counteract the low social proximity, researchers have argued that the success of youth programs is dependent on ‘champion’ professionals (Aisbett et al., 2007; Boyd, Hayes, Wilson, \& Bearsley-Smith, 2008). Without qualified, committed professionals and funding, innovative services such as the YACs are likely to fail (Boyd et al., 2008; Degotardi, 2008). Indeed, the current study identified problems with retention of champions due to it being financially unrewarding, time consuming and leading to burnout.

With lack of funding significantly restricting services provided, the high social proximity and financial support of the Gippsland rural communities allowed the YAC programs to overcome these barriers. This high social proximity builds trust for the service and can lead to early detection of mental illness (Aisbett et al., 2007; Hodges et al., 2007). Furthermore, funding from the Gippsland PHN and other donating organisations, helped YACs fulfil the need for bulk-billing and free services for young people, subsidise staff income shortfalls, provide reception and fund additional equipment.

Experienced staff with a youth-friendly approach were shown by the current study and past research as an essential ingredient to providing successful youth programs (Aisbett et al., 2007; Boyd et al., 2007; Boyd et al., 2008). Similar to Boyd et al. (2007), the present research found that staff who were multi-skilled, approachable, easy to talk to, followed-up, 
and were able to build positive rapport, enhanced attendance rates of young people accessing YACs. The staff characteristics identified in this study were also associated with Boyd et al. (2008) notion of 'champions', who were youth-friendly, qualified and committed.

As headspace continues to expand in rural and regional areas, future research could explore the integration of this program focusing on the enablers and barriers associated with the partnership between headspace and YACs. This research can capture information pertaining to the essential ingredients needed to successfully integrate new service models into rural settings. As previous research has highlighted the importance of working with the community to provide local solutions, this research could provide a detailed description of the transference and integration of local knowledge into new headspace services (Edwards et al., 2014; Hodges et al., 2007).

As the present study is based in Gippsland South Coast and utilised a convenience sample, the findings may not be generalisable to other rural communities and may be susceptible to sampling error (Aron, Coups, \& Aron, 2013). Future research could compare YAC service models with other rural services in order to enhance the generalisability of these findings. Another limitation of the current study could be the female dominated sample, as the male perspective was underrepresented. Hence, future research could also investigate the male perspectives from both young people attending and staff working within YACs.

Consistent with previous research, the current study has identified a number of barriers and enablers to services accessibility for young people residing in rural communities. Barriers included transport, low social proximity, parent consent, limited services, funding 
and recruitment of staff. Enablers identified in the present study included community support, bulk billing services, funding from GPHN, creation of the consortium, youth-friendly practitioners, trust, and partnerships with the community and other services. With funding being highlighted as the number one barrier and enabler to service delivery, ongoing funding is essential to aid the continuation of these successful community-driven programs.

In conclusion, the YAC programs have successfully provided youth-friendly services which are community specific and able to address the local needs of youth residing in Gippsland South Coast. The successful integration of headspace into the South Coast region will be dependent on its ability to work in partnership with the already successful YAC services. Providing additional outreach services to YACs would allow each program to address youth needs as well as build trust amongst the community for the new headspace model and brand. Complementary services will directly address the limited access to specialists in rural areas and offer alternative programs for young people. This is important as YACs have limited opening hours and the support of headspace can provide additional service at additional times for young people. Further, funding support from headspace to increase YACs opening hours, would allow for the continuation of YAC services and provide support to young people who are unable to travel to Wonthaggi for headspace support. The success of a new service model will likely depend on learning from what has already worked in some of the many small communities in this region. Beyond learning, further success and uptake of new service offerings will be enhanced through working with the YAC consortia which has developed from community need, with community support and which has added positively to the social capital of each community. 
Acknowledgements and Funding: This study was supported by funds from Gippsland Primary Health Network. ED is supported by a scholarship from Australian Rotary Health. KA is supported by a Career Development Fellowship (APP1141207) from the National Health and Medical Research Council, Australia. These funding bodies had no role in the design or conduct of the study or interpretation of the findings. We thank all staff who are part of the YAC consortium and young people for their support of this study.

Conflict of interest: All authors declare no conflict of interest

\section{References}

Aisbett, D. L., Boyd, C. P., Francis, K. J., Newnham, K., \& Newnham, K. (2007). Understanding barriers to mental health service utilization for adolescents in rural Australia. Rural Remote Health, 7(1), 624.

Aron, A., Coups, E. J., \& Aron, E. (2013). Statistics for psychology. Boston: Pearson.

Boyd, C., Aisbett, D. L., Francis, K., Kelly, M., Newnham, K., \& Newnham, K. (2006). Issues in rural adolescent mental health in Australia. Rural Remote Health, 6(1), 501.

Boyd, C., Francis, K., Aisbett, D., Newnham, K., Sewell, J., Dawes, G., \& Nurse, S. (2007). Australian rural adolescents' experiences of accessing psychological help for a mental health problem. Aust J Rural Health, 15(3), 196-200. doi:10.1111/j.1440-1584.2007.00884.x

Boyd, C., Hayes, L., Nurse, S., Aisbett, D. L., Francis, K., Newnham, K., \& Sewell, J. (2011). Preferences and intention of rural adolescents toward seeking help for mental health problems. Rural Remote Health, 11(1), 1582.

Boyd, C., Hayes, L., Wilson, R. L., \& Bearsley-Smith, C. (2008). Harnessing the social capital of rural communities for youth mental health: an asset-based community development framework. Aust J Rural Health, 16(4), 189-193. doi:10.1111/j.1440-1584.2008.00996.x

Braun, V., \& Clarke, V. (2012). Thematic analysis APA handbook of research methods in psychology, Vol 2: Research designs: Quantitative, qualitative, neuropsychological, and biological. (pp. 57-71). Washington, DC, US: American Psychological Association.

Chan, G. C., Leung, J., Quinn, C., Kelly, A. B., Connor, J. P., Weier, M., \& Hall, W. D. (2016). Rural and Urban Differences in Adolescent Alcohol Use, Alcohol Supply, and Parental Drinking. J Rural Health, 32(3), 280-286. doi:10.1111/jrh.12151

Clarke, M., Kuosmanen, T., \& Barry, M. (2015). A Systematic Review of Online Youth Mental Health Promotion and Prevention Interventions. Journal of Youth and Adolescence, 44(1), 90-113. doi:10.1007/s10964-014-0165-0

Crouch, M., McKenzie, H. (2006). The logic of small samples in interview-based qualitative research. Social Science Information, 45, 483-499.

Curtis, A. C., Waters, C. M., \& Brindis, C. (2011). Rural adolescent health: the importance of prevention services in the rural community. J Rural Health, 27(1), 60-71. doi:10.1111/j.17480361.2010.00319.x

Degotardi, V. A. (2008). Current models of child and adolescent mental health service delivery. Med J Aust, 189(9), 507-508.

This article is protected by copyright. All rights reserved. 
Edwards, M. B., Theriault, D. S., Shores, K. A., \& Melton, K. M. (2014). Promoting youth physical activity in rural southern communities: practitioner perceptions of environmental opportunities and barriers. J Rural Health, 30(4), 379-387. doi:10.1111/jrh.12072

Ervin, K., Phillips, J., \& Tomnay, J. (2014). Establishing a clinic for young people in a rural setting: a community initiative to meet the needs of rural adolescents. Aust J Prim Health, 20(2), 128133. doi:10.1071/py12157

Fox, J., Merwin, E., \& Blank, M. (1995). De facto mental health services in the rural south. J Health Care Poor Underserved, 6(4), 434-468.

Gibson, K. L., Coulson, H., Miles, R., Kakekakekung, C., Daniels, E., \& O'Donnell, S. (2011). Conversations on telemental health: listening to remote and rural First Nations communities. Rural Remote Health, 11(2), 1656.

Guest, G., Bunce, A., \& Johnson, L. (2006). How many interviews are enough? An experiment with data saturation and variability. Field Methods, 18(1), 59-82.

Hardy, C. L., Kelly, K. D., \& Voaklander, D. (2011). Does rural residence limit access to mental health services? Rural Remote Health, 11(4), 1766.

Hodges, C. A., O'Brien, M. S., \& McGorry, P. D. (2007). headspace: National Youth Mental Health Foundation: Making headway with rural young people and their mental health. Australian Journal of Rural Health, 15(2), 77-80. doi:doi:10.1111/j.1440-1584.2007.00868.x

Hodges Craig, A., O'Brien Matthew, S., \& McGorry Patrick, D. (2007). headspace: National Youth Mental Health Foundation: Making headway with rural young people and their mental health. Australian Journal of Rural Health, 15(2), 77-80. doi:10.1111/j.14401584.2007.00868.x

Myers, K., \& Cornor, J. S. (2016). The Case for Telemental Health for Improving the Accessibility and Quality of Children's Mental Health Services. Journal of Child and Adolescent Psychopharmacology, 26(3), 186-191. doi:10.1089/cap.2015.0055

Sawyer, M. G., Arney, F. M., Baghurst, P. A., Clark, J. J., Graetz, B. W., Kosky, R. J., . . Zubrick, S. R. (2001). The Mental Health of Young People in Australia: Key Findings from the Child and Adolescent Component of the National Survey of Mental Health and Well-Being. Australian \& New Zealand Journal of Psychiatry, 35(6), 806-814. doi:10.1046/j.1440-1614.2001.00964.x

Sullivan, G., Duan, N., Mukherjee, S., Kirchner, J., Perry, D., \& Henderson, K. (2005). The Role of Services Researchers in Facilitating Intervention Research. Psychiatric Services, 56(5), 537542. doi:10.1176/appi.ps.56.5.537

Turner, L., Spencer, L., Strugnell, J., Di Tommaso, I., Tate, M., Allen, P., . . Chang, J. (2017). Young people have their say: What makes a youth-friendly general practice? Aust Fam Physician, 46(1), 70-74.

Xu, Q., \& Chow, J. C. (2006). Urban community in China: service, participation and development. International Journal of Social Welfare, 15(3), 199-208. doi:10.1111/j.14682397.2006.00419.x

\section{Figure Legends}

Figure 1: Gippsland Region, Victoria. 
Figure 2: Environmental Barriers

Figure 3: Service Barriers Young People

Figure 4: Client Barriers

This article is protected by copyright. All rights reserved. 


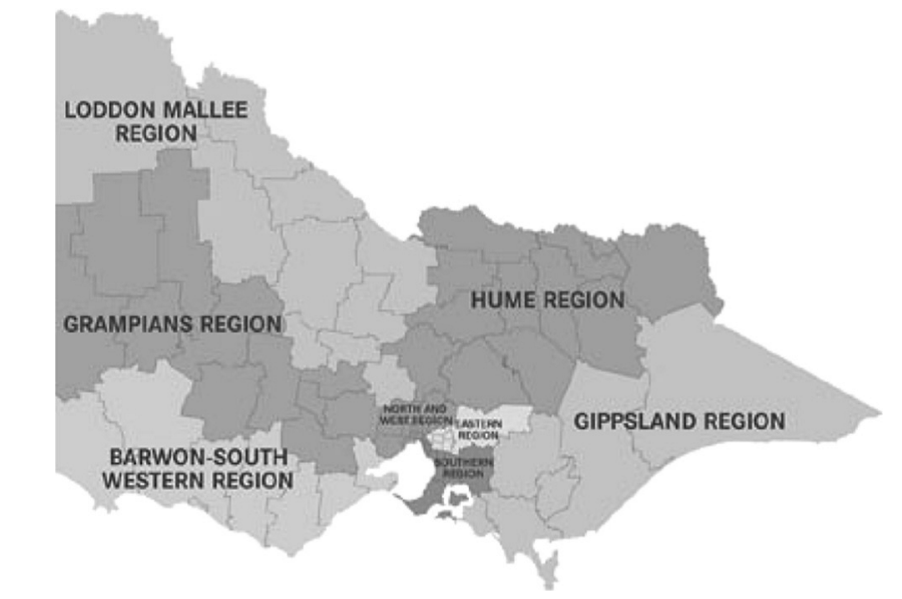

EIP_12949_Figure 1 Gippsland Region, Victoria300.tif

This article is protected by copyright. All rights reserved. 


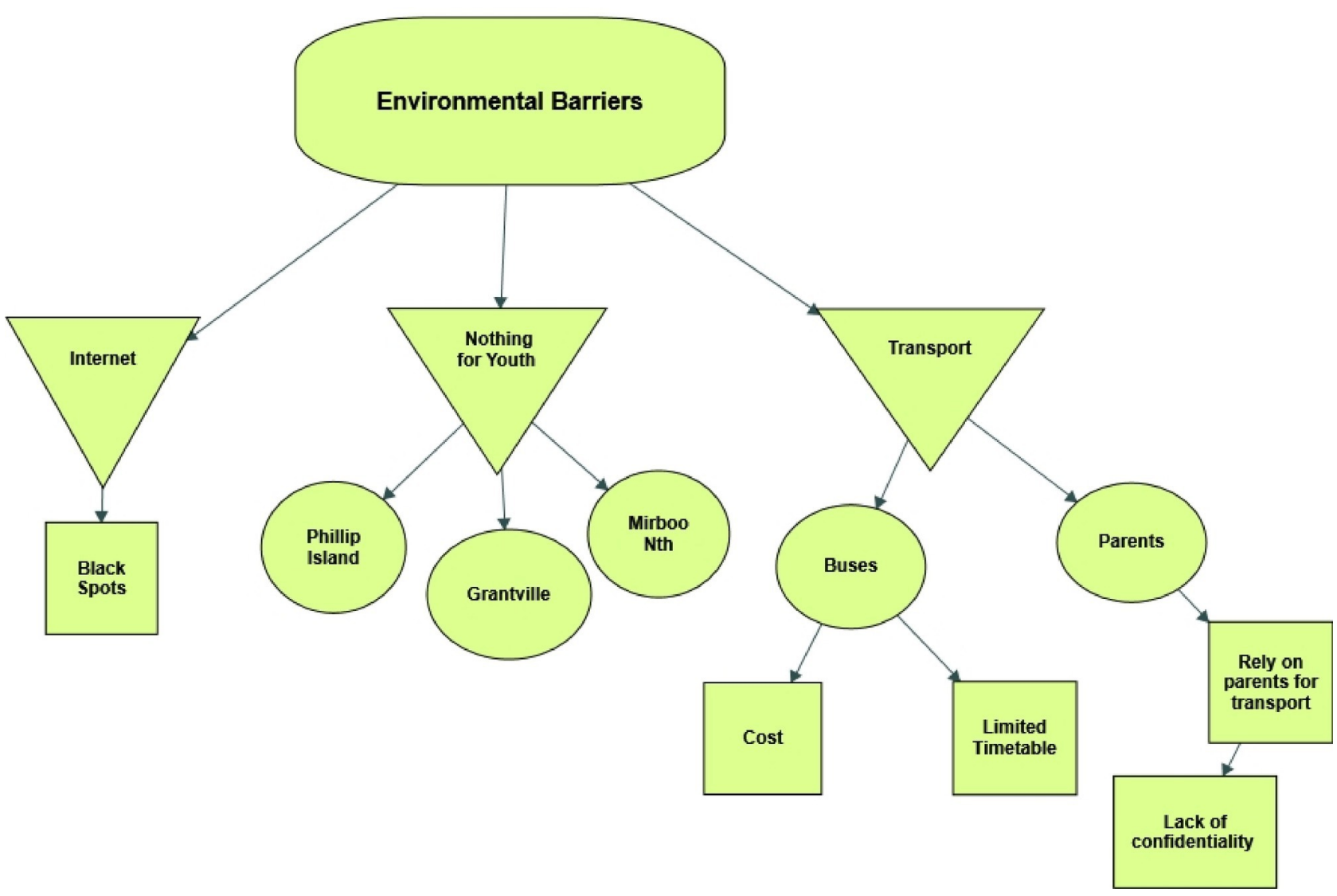

eip_12949_figure 2 environmental barriers300.eps

This article is protected by copyright. All rights reserved. 


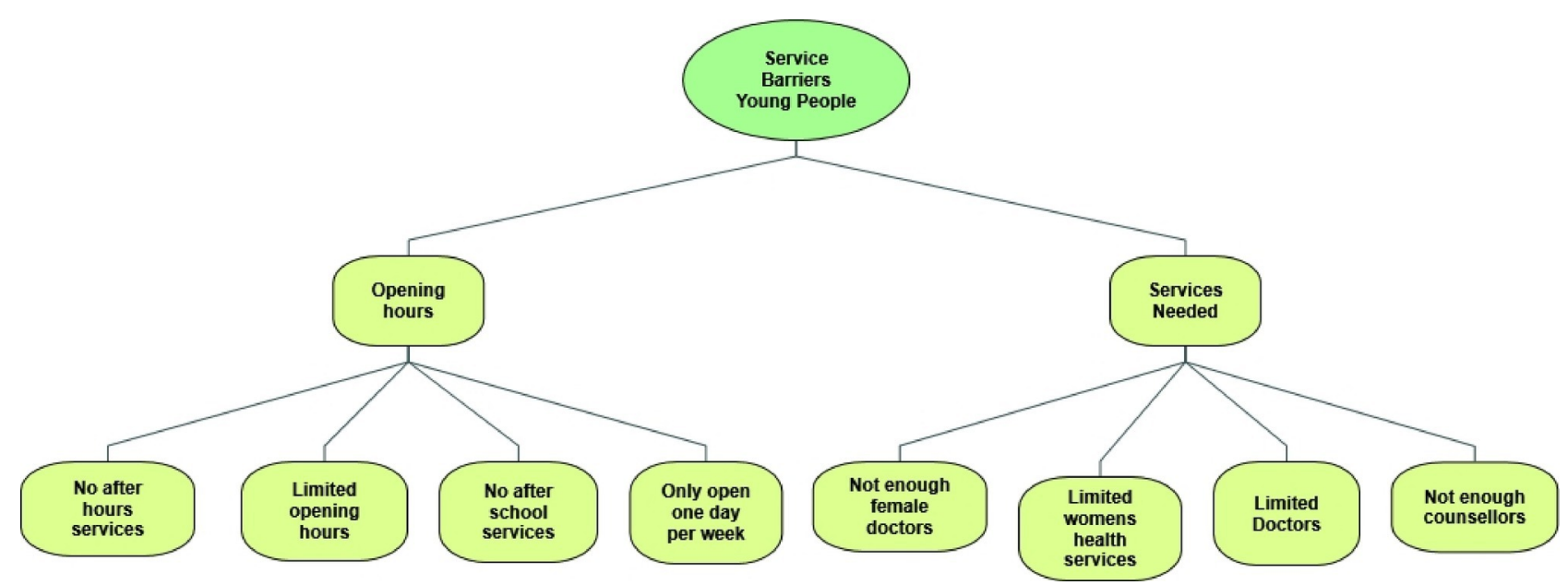

eip_12949_figure 3 service barriers young people300.eps 


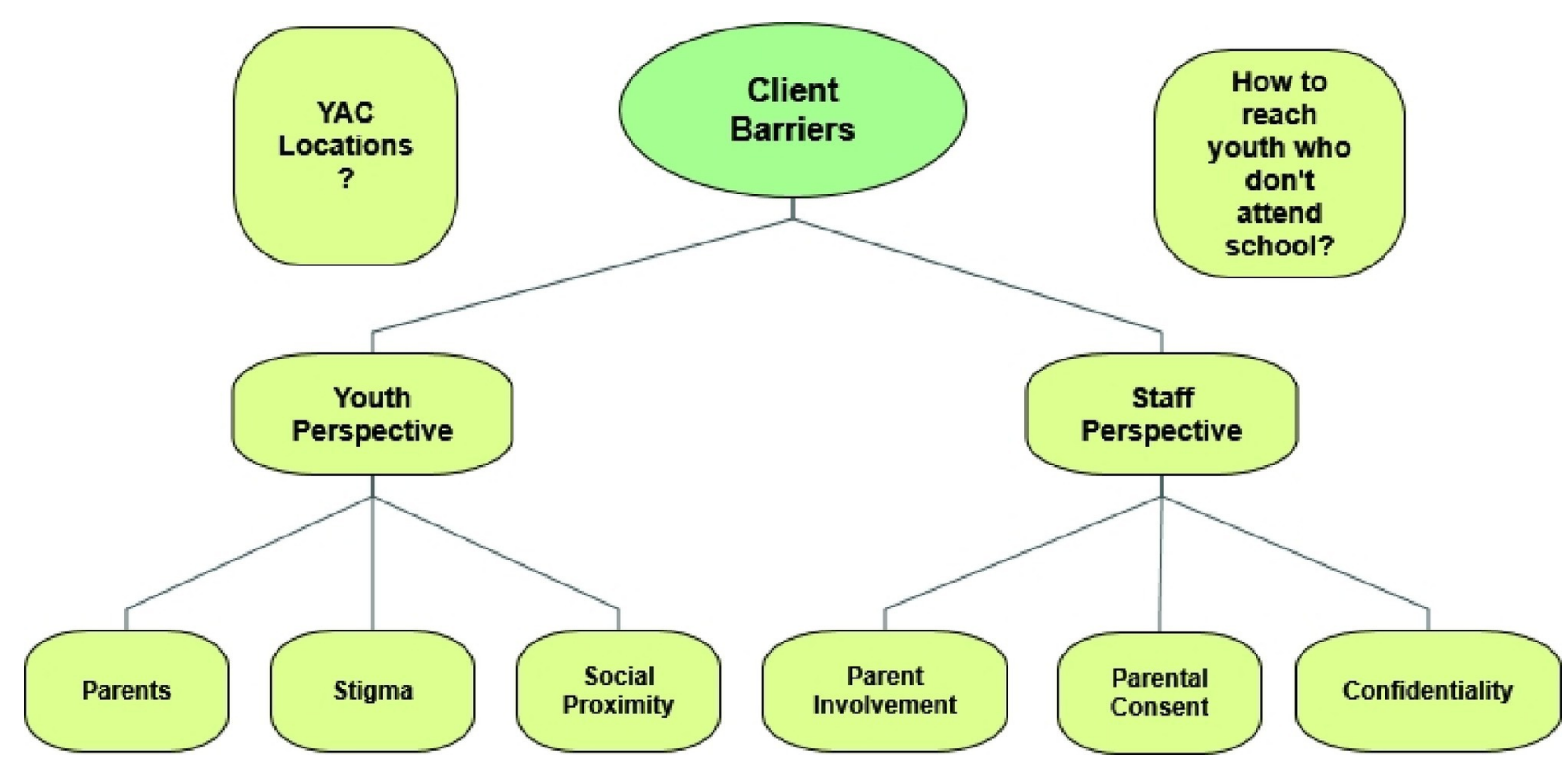

eip_12949_figure 4 client barriers300.eps

This article is protected by copyright. All rights reserved. 


\section{University Library}

\section{- M M N E R VA A gateway to Melbourne's research publications}

Minerva Access is the Institutional Repository of The University of Melbourne

Author/s:

Dolan, E;Allott, K;Proposch, A;Hamilton, M;Killackey, E

Title:

Youth access clinics in Gippsland: Barriers and enablers to service accessibility in rural settings

Date:

2020-02-13

Citation:

Dolan, E., Allott, K., Proposch, A., Hamilton, M. \& Killackey, E. (2020). Youth access

clinics in Gippsland: Barriers and enablers to service accessibility in rural settings. EARLY

INTERVENTION IN PSYCHIATRY, 14 (6), pp.734-740. https://doi.org/10.1111/eip.12949.

Persistent Link:

http://hdl.handle.net/11343/275406 